\title{
Social Justice in a Multicultural Society: Experience from the UK
}

Gary Craig ${ }^{1}$, University of Hull

\begin{abstract}
Social justice is a contested concept. For example, some on the left argue for equality of outcomes, those on the right for equality of opportunities, and there are differing emphases on the roles of state, market and individual in achieving a socially just society. These differences in emphasis are critical when it comes to examining the impact that public policy has on minority ethnic groups. Social justice should not be cultureblind any more than it can be gender-blind yet the overwhelming burden of evidence from the UK shows that public policy, despite the political rhetoric of fifty years of governments since large-scale immigration started, has failed to deliver social justice to Britain's minorities. In terms of outcomes, in respect for and recognition of diversity and difference, in their treatment, and in the failure of governments to offer an effective voice to minorities, the latter continue to be marginalised in British social, economic and political life. This is not an argument for abandoning the project of multiculturalism, however, but for ensuring that it is framed within the values of social justice.
\end{abstract}

\section{Social Justice in the UK: Current Political Discourse}

Social justice is a concept that has been debated--in different guises--for thousands of years. It is only since the 1970s, however, and particularly in the past fifteen years, that it has re-emerged into political discourse, most notably amongst governments which have characterized themselves as social democratic or “Third Way.” As Miller argues (2001), in the context of the development of liberal democratic societies, "the quest for social justice is a natural consequence of the spread of enlightenment” (p. 4). In this article, we examine the meaning of the term "social justice," particularly in a UK context, deriving a wide-ranging definition which draws on literature, policy and practice. We then apply its principles to the position of minority ethnic groups within the UK, to see the extent to which the policy framework of government and the outcomes of that policy framework for minorities can be said to be socially just.

The concept itself remains a contested one, adopted from a variety of political positions, and linking to wider arguments about the roles of the state, the market, and the individual. Although contemporary social democratic governments appear to "own" the approach of social justice, it has also been espoused from the political right in the UK and in Australia, where, for example, the government argues that social justice is achieved best through an approach which privileges individualism - when individuals are able to

\footnotetext{
${ }^{1}$ Professor of Social Justice, Centre for Social Inclusion and Social Justice, University of Hull, Hull, HU6 7RX UK tel 0044 (0)1482 465780 email G.Craig@hull.ac.uk
} 
compete in the market place, unconstrained by the action of the state. Current arguments about social justice also expose the tensions with other overarching political goals of economic competitiveness and environmental sustainability (JRF, 2004).

The concept of social justice received prominence within the United Kingdom with the work of the Commission for Social Justice established by the, then Leader, of the Labour Party (CSJ 1994). In a context of deepening inequality and poverty--the UK was then, in income terms, amongst the most unequal countries in the developed world--the Commission suggested that the elements of social justice would include:

- the equal worth of all citizens

- the equal right to be able to meet their basic needs

- the need to spread opportunities and life chances as widely as possible

- the requirement that we reduce and, where possible, eliminate unjustified inequalities.

This list begged important political questions. The policy programme of UK New Labour governments, and similarly disposed governments elsewhere--continue to beg some of them; for example, questions of what basic needs are. Social democratic governments provide systems of social assistance of varying levels of generosity, but have not effectively defined the adequacy of that assistance to meet "basic needs" (as defined by a range of participatory research studies, see ex. in Gordon et al., 2000). The UK government's programmes to address social exclusion and reduce poverty are titled Opportunity for All (e.g. DWP, 2005); however, most such governments do not go beyond goals related to equality of opportunity to promote equality of outcome, which many would argue is a more robust indicator of a socially just society.

Critics of social democratic governments argue that the state has to intervene more strongly to promote social justice, both in terms of the process by which it is achieved and by constructing redistributive policies. The market - covering all the institutions of society which operate to deliver goods and services - distributes those goods and services, as well as opportunities (or life chances) unfairly. Therefore the state should have a key role in correcting those deficiencies. Governments focusing only on the poor and disadvantaged are also failing one key test of social justice, which is to ensure the fair distribution of the good and bad things across the whole of society and not just amongst the poor. Redistribution between different groups of poor people is not socially just redistribution and a socially just agenda would need to confront the huge disparities in income and wealth which remain within the UK and in many other countries. In the UK, the adoption of the goal of social justice--with a stated commitment to an agenda of equalities--has been used to mark off the policy agenda of the Scottish Executive as being more radical and redistributive than that of the UK Parliament (Scottish Executive, 2003). However, the Scottish Executive, again, goes only some way towards a position of fairness to all: its 2003 spending manifesto argued that "Scotland must be a society of strong inclusive communities where everyone can live with dignity ... every policy we introduce ... will be measured against success in closing the gap between the most disadvantaged and the average.” Recent commentary suggests however that Scotland too, despite its rhetoric, has some way to go to grasp the thistle of social justice (Goodlad, 2005). 


\section{Ideas of Social Justice}

A key modern protagonist for the concept of social justice was John Rawls (Rawls, 1971). Drawing on Aristotle, Hume, Hegel, Kant and other moral philosophers, he argued that (Social) Justice meant "fairness ... the principle subject of justice is the basic structure of society ... the way in which the major social institutions distribute fundamental rights and duties and determine the division of advantages from social cooperation...," (p. 6) -- that is, he was not concerned with the benefits to be derived for individuals from private association. A "well-ordered society" was one in which "everyone is presumed to act justly ..." (p. 8), where vested interests are put to one side. Rawls' assertion of the idea of social justice as incompatible with a society oriented towards individual gain is echoed in Donnison (1998) who argues that "standards and values cannot be developed privately" (p. 186), i.e. within one institution, or in relation to one practice. What, Donnison suggested, "we apply to others we must apply to ourselves." These approaches are grounded in the traditions of a redistributive modern welfare state.

Rawls then derived two basic principles:

1. "each person is to have an equal right to the most extensive scheme of equal basic liberties compatible with a similar scheme of liberties for others ...

2. social and economic inequalities are to be arranged so that they are both (a) reasonably expected to be to everyone's advantage, and (b) attached to positions and offices open to all” (p. 53).

Social justice thus has a clear inter-relationship with the concept of inequality. These principles were specific formulations of a more general position, that "all social values - liberty and opportunity, income and wealth, and the social bases of self-respect are to be distributed equally unless an unequal distribution of any or all of these values is to everyone's advantage” (p. 59). The obverse concept, injustice, thus becomes in Rawls' view, "simply inequalities that are not to the benefit of all" (Ibid). Much inequality is unacceptable but some areas of inequality are acceptable where they are of wider benefit. For example, one might consider people who have undergone long periods of training, such as doctors, teachers or lawyers--or who are placed in more risky situations--such as firefighters, deep sea fishers or train drivers--to undertake key roles in society. It is reasonable that they should be rewarded but, at the same time, important also to recognize that the obscene disparities in income and wealth which characterize most societies are not socially just, particularly as much of that income and wealth is earned at the expense of others' poorly-paid labour. This approach also highlights distinctions between equality of opportunity or access, equality of outcome, and equality of status.

As noted above, most contemporary UK politicians promoting the concept of equality tend to argue for equality of opportunity; however, those on the political right emphasize simply equality of rules and processes, the state's role being merely to ensure free market exchanges for all (equally). Those broadly on the left, argue for equality of outcome - or at least sufficient equality of outcome to prevent injustice. Technically, all full citizens in the UK have equality of status; however, equality of opportunity and access, and of outcome, say, for black and minority ethnic groups or for women or disabled people, are clearly not present, as we will demonstrate. It is clear from educational statistics, that equality of opportunity - in the sense that everyone starts 
school more or less at the same point - is not itself enough to achieve social justice. For example, the impact of racism in educational systems means that many minority ethnic children fall far behind the average in attainment by the time they leave school (Gillborn and Mirza, 2000; Craig, 2003; Craig, 2006). This is but one example of Lister's critique that "what is not yet acknowledged is that genuine equality of opportunity and recognition of the equal worth of all our citizens is incompatible with the savagely unequal society we now live in. Equality of opportunity in the context of economic and social structures that remain profoundly unequal is likely to remain a mirage" (quoted in NICF, 2001). This perspective is echoed in a recent analysis of the performance of New Labour since it came to power in 1997, which argues that the UK still has a poor record for reducing levels of child poverty and that, despite New Labour's rhetoric on combating inequality, the gap between rich and poor has grown in the past few years (Paxton and Dixon, 2004).

Rawls then observed that if there were to be inequalities, they could only be justified on the basis that everyone had equality of opportunity to compete for the most desirable positions, regardless of their class or status. Of course, most posts in society are not open equally to all because of the cumulative impact of disadvantages such as "race," gender and social class. Rawls' famous test of social justice was through what he called the "veil of ignorance," through which "no-one knows his place in society, class position or social status ... they know that their society is subject to the circumstances of justice and whatever this implies” (op. cit., pp. 118-119). People, thus, would act without any sense of personal advantage.

Miller argues that social justice-which he regards as interchangeable with the concept of distributive justice-provides the political and philosophical basis for deciding "how the good and bad things in life should be distributed among the members of a human society" (2001, p. 1). These things incorporate, in his view, the familiar material dimensions of a "good life" - income, wealth, education, housing, health and so on. Miller identifies three key principles which connect strongly to the concept of social justice: desert (i.e. what we deserve; need; and equality).

In relation to desert, a just society is one "whose institutions are arranged so that people get the benefits they deserve.” (Ibid. 155) This principle must not however become a rigid formulation contingent simply on institutional arrangements within a society, but allow concepts of need to come into play (i.e. resources cannot be committed solely on the basis of desert but also of need). We may imprison people because of their crimes but that does not mean that we may starve them at the same time. The concept of need is "not merely idiosyncratic or confined to those who hold a particular view of the good life ... it must be capable of being validated on terms that all relevant parties can agree to" (Ibid. 205). This validation is a political process, but one from which many parties have hitherto been excluded because of their lack of power, both in a formal and informal sense. In particular, as we will again argue, black and minority ethnic groups in the UK have hitherto been excluded from decision-making and most significantly from determining their own conceptions of need. Indeed, black and minority ethnic groups are increasingly becoming resistant in the UK to research done "on" them without either their involvement in determining what the questions are which are to be asked or some sense that the research leads to demonstrable policy change (Butt and O’Neil, 2004). 
Miller also argues that the notion of equality relevant to social justice is distributive in its nature: "it specifies that benefits of a certain kind - rights, for instance - should be distributed equally because justice requires this” (op. cit. pp. 232). To achieve social justice, we must have "a political community in which citizens are treated in an equal across-the-board way, in which public policy is geared toward meeting the intrinsic needs of every member, and in which the economy is framed and constrained in such a way that the income and other work-related benefits people receive correspond to their respective deserts" (Ibid. 250).

The concept of social justice is thus linked closely to other key concepts such as need, citizenship, and rights. Marshall's historic exposition of citizenship and social class (Marshall, 1950) advanced taxonomy of rights by which one could identify the characteristics of citizenship. These incorporated:

- civil rights: property rights, legal guarantees and freedoms;

- political rights: right to vote, rights of association, constitutional participation; and

- social rights: entitlements to basic standards of education, health and social care, housing and income maintenance.

Many contemporary commentators on citizenship, such as Lister (2003) and Dean and Melrose (1999) do not regard these rights as of equal weight. Dean and Melrose for example, argue that "Civil rights underwrite the operation of the market economy and are entirely consistent with class inequality" whereas "political rights and social rights tend to challenge such inequality" (p. 180). Thus citizenship and class, to a large extent, can embody opposing principles. From this perspective, there, again, remains a major political question about the degree to which social justice is compatible at all with the operation of a market economy; the model of economic relations strongly promoted by New Labour and other social democratic governments. Doyal and Gough (1991) argue that social justice "stands against fanatics of the free market economy ... but also demands and promotes economic success" or, conversely, that "social justice is an ideal in its own right but economic success also demands a greater measure of social justice" (130). Plant (2000), however, a key theoretician for the New Labour project, argues that social justice requires governments to work with the grain of the market. For many commentators, however, the market is increasingly seen to be the fundamental cause of much injustice, both social and economic, and the goal of social justice as fairness demands that governments confront the inequities of market systems.

Most contemporary liberal conceptions of social justice generally place social and political rights far ahead of civil rights in the sense in which Marshall used them. Confusingly, civil rights have come in the past forty years, most of all through the political activism of Blacks in the Southern United States of America, more to mean social and political rights - such as freedom to attend racially mixed ('integrated') schools - than the more narrow meaning ascribed them by Marshall. Earlier analyses of social justice are also limited in their understanding of the way in which the dimensions of gender and culture need to be built into a framework of values; to Marshall's typology we would need to add, following Castles (2000), Lister (2003) and others, the categories of cultural rights and gender rights. For minority ethnic groups, this means the right to be 
culturally different within a society--within certain parameters ${ }^{2}$--which provides the same social, civil and political rights to all.

\section{Social Justice in Multicultural Societies}

This raises the important theoretical and political agenda of exploring the nature of social justice within multicultural societies and particularly those characterized by institutional and individual racism. Multicultural societies have increasingly been struggling with the difficulties of incorporating respect and recognition for cultural diversity and difference within a framework of universal rights: respect and recognition for minorities might be seen as ways in which equality of status, of common citizenship, are put into operation. At present, within the UK, arguments about cultural and ethnic diversity have moved away from the notion of multiculturalism and are increasingly couched in terms of debates about social integration, assimilation and cohesion rather than about social justice. Social injustice might however be said to emerge not just from the unconstrained workings of institutions, groups and organisations through the mechanisms of the market, which lead to significant differences in income, wealth and the opportunities and outcomes these bring, but also because of cultural and socially-constructed differences based on, for example, gender, ethnicity, sexuality and disability (Fraser, 2001). We will return to the question of multiculturalism below.

Social justice is also about the non-material aspects of life. These incorporate critical dimensions of respect and recognition between different groups and individuals (and not just the poor). For Miller, the distributive notion of social justice is not to be confused with "the ideal of a society in which people regard and treat one another as equals ... [which] ... is not a distributive ideal in itself but does have distributive implications" (Op. cit., pp. 232, 241). For example, such a conception can influence our attempts at distributive justice. This latter concept he terms social equality, which "is a matter of how people regard one another and how they conduct their social relations'. (op. cit. 239). This complementary "recognition" or "relations of respect" aspect of social justice has been strongly argued in recent years by e.g. Young (1990). For her, social justice as a distributive issue has to be set within a relational and cultural context, in particular "the elimination of institutionalized domination and oppression" (p.30). Individuals, as well as the state and the market, have a key role to play in supporting the goals of social justice and answering the sorts of deceptively simple question posed by Miller in relation to social justice between the genders: "is it fair that women should perform more domestic labour than men?” (2001, p. 5) or, to link more closely to the theme of this article, is it fair that certain minorities should end up in particularly exploited sections of the labour market?

Miller argues that the major challenge posed by multiculturalism is that it widens the notion of the closed political community within which concepts such as need, rights, and desert are usually contested. However, this is not an argument for "the elimination of cultural differences but the opening up of national identities so that they become accessible to the members of many (ideally all) cultural groups within existing

\footnotetext{
${ }^{2}$ In most multicultural societies, there are lively political debates now about what these parameters should be (see Parekh, 2002); increasingly, they are being more tightly drawn at present.
} 
democratic states” (2001, p. 263). The political task, then, is to ensure that all cultural groups are, first, recognized and secondly, fully engaged in the process of determining the principles of social justice and acting on those principles. It is clear, as Miller argues, that there is little empirical evidence which supports the view that cultural differences translate into differing conceptions or principles of social justice, although the way those principles are reflected in differing practices may vary. The important point is that social justice cannot be blind to issues of culture but this is, in any case, an area which has yet to be explored in any depth. We do know that the achievement of equally socially just outcomes, in terms of meeting need and so on, is markedly variable from one so-called multicultural country to another. To some degree this variability is a reflection of the structural constraints under which governments operate; in terms, for example, of the historical development of formal political constitutions or informal political settlements. Government's preparedness to tolerate--or reject-structural racism, however, plays an equally important part.

In France, for example, ethnicity is not regarded as a legitimate factor in the determination of citizenship because of the Republican constitution of 1789. Minorities are thus effectively "written out" of the policy process to a large degree ${ }^{3}$ and, for example, from research which describes the level and type of disadvantage that they face. In Germany, jus sanguinis, basing citizenship on the rights of blood ties rather than on jus solis, of residence, has meant that the aussiedler returning to Germany from Poland and Russia have greater rights to citizenship than, say, migrants of Turkish origin who have lived and worked in Germany for thirty years and have children born in Germany. ${ }^{4}$ In Malaysia, whose population is very roughly divided equally between people of Malay, Chinese and Indian origin, economically successful Chinese people and academically successful Indian people find their advancement through many avenues blocked because the Malay constitution enhances the rights of Malays and discriminates in their favour. In New Zealand, despite the provisions of the Treaty of Waitangi which provided legal protection for the Maori, at least in terms of land rights, they are still to be found most strongly amongst those who are unemployed, in the prison population and in areas marked by social and economic deprivation. And in Australia, the treatment of the aboriginal Kuri people has been even more shameful as their relatively weak land rights are now under threat; indeed, social and economic policy towards them might be regarded as a legacy of the ethnic cleansing of the nineteenth century, carried on by other means. In Canada, the federal government has at least publicly apologized to the Inuit for its oppressive treatment of them over the past two hundred years although, more generally, there is strong evidence that poverty, ill-health and poor social and economic conditions are strongly racialized (Galabuzi, 2006).

\footnotetext{
${ }^{3}$ The "hidden" nature of poverty and poor housing conditions experienced by many migrants living in Paris, and their exclusion from much social policy, has been used to explain the disturbances which took place in the autumn of 2005.

${ }^{4}$ Belatedly, this injustice is being recognized with the children of long-settled migrants being offered German citizenship: for further discussion, see Craig, 2003.
} 


\section{Other Dimensions of Social Justice}

Most major conceptions of social justice fail to consider the role of those most disadvantaged by social injustice, as actors - rather than simply victims - in the search for social justice. The United Nations (see e.g. UNDP, 1997) points to the many ways, including organizational, informational, developmental, constitutional and legal, political and economic ways, in which participation by the disadvantaged themselves may promote social justice. Many governments have now also acknowledged the importance of processes which empower the disadvantaged to act and speak on their own behalves. An additional dimension to social justice might thus be the role of community development as the means by which the excluded and the marginalized can act in the search for social justice. This action incorporates the dimension of "voice," of being able to articulate one's own needs and desires through participation at all levels in the policy process. To put it another way, social justice is not simply about achieving forms of human welfare--of whatever kind--but the means by which that welfare is obtained. Process is as important as outcome. This has been one of the major contributions which community development and the activities of social movements--for recognition of rights in relation to disability, sexuality and so on--have made to the search for social justice. Voice is also, as Lister argues, a way in which those who are materially poor can challenge the way in which much of the rest of society exploits the poverty of those on low income to imply an inferior status--their "othering”--as human beings (Lister, 2004). It has also been argued (see e.g. JRF, 2004) that geography has an important influence on the achievement of social justice. Differential equality of opportunity, poverty, access to rights and so on, may be accentuated, for example, for those in rural areas as compared with their urban counterparts, (e.g. the costs of accessing goods and services and their frequently poorer quality), or those living in deteriorating neighbourhoods compared with those in well-resourced communities. Social justice has a spatial dimension and, in thinking about this, we need to think carefully about different conceptions of poverty and need in different contexts--and for different groups--in the population. The position of many medical consultants of Indian origin working in rural areas in the UK is a good example of the need for careful analysis. Whilst rural areas are often portrayed as comfortable, higher income areas, the reason why many Indian doctors end up working in rural areas is because they have faced racial discrimination and barriers in accessing the higher profile and status posts in teaching hospitals in urban areas, and are thus directed towards posts of lower status, including in rural areas. Their higher profile in rural areas where the proportion of minorities in relatively small - exposes them to further racism (see e.g. Henderson and Kaur, 1999).

Drawing on these analyses, one wide-ranging definition of social justice might thus be as follows:

a framework of political objectives, pursued through social, economic, environmental and political policies, based on an acceptance of difference and diversity, and informed by values concerned with

- achieving fairness, equality of outcomes and treatment;

- recognizing the dignity and equal worth and encouraging the self-esteem of all;

- the meeting of basic needs;

- reducing inequalities in wealth, income and life chances; and 
- the participation of all, including the most disadvantaged.

Finally, of course, in thinking about social justice conceptually, we have to acknowledge that we can no longer think about it in the context of one country. It is increasingly necessary to consider how the process of globalization--that is, the impact of economic groupings which have no allegiance to particular political entities--affects this approach. In Miller's and earlier writers' analyses, it was possible to define social justice within the context of a closed political community in which all relevant actors could be identified and encouraged to engage politically with the debates about social justice. Globalization, according to many commentators, has generated increasing divisions, in terms of income and wealth, both between and within all nation states (see e.g. Hirst and Thompson, 1999; Venters, 2002) and we have to respond to this analysis by thinking about how social justice can be understood at a transnational level. This idea is largely beyond the scope of this article but two more limited political scenarios might be advanced to protect the claims of social justice in this context: one is that each nation state can continue to argue the merits of social justice, the other that a transnational community and its institutions might emerge (which the European Union, for example, might represent within the context of Europe) which can constitute the new closed political community. Alternatively, those concerned with issues of social justice between states and regions could choose not to retreat within such a closed community but use it as a base for advancing political, economic, social and environmental arguments for global (social) justice. This is a major political project for the future.

\section{Social Justice and Britain's Minorities}

We can now review whether these principles of social justice operate to the practical benefit of black and minority ethnic groups in the UK, which has been regarded as a multicultural society for many years, particularly since the large-scale immigration of the 1950s-1970s. There is not space within this article to review the fairly extensive research evidence in detail but some pointers to the key literature will be provided. First of all, let us look at the issue of equality of status, and the particular dimensions of respect and recognition. Technically, as noted earlier, all citizens of the UK, of whatever ethnicity, have an equal status as citizens. The minority ethnic population in the UK is now $8 \%$ as a whole ${ }^{5}$ but this population is not equally distributed: there are two London boroughs which have a minority population which is now actually in a majority and many urban areas have minority populations of more than $15 \%$ of the total population. Migration to the UK over the past 60 years, largely from former colonies, has been and continues to be predominantly driven by the labour market needs of the British economy, together with consequent family reunion. The minority population has grown more recently partly through natural population growth (about half of the current minority population was actually born in the UK) and partly in recent years through the growth of refugees (although their numbers are much smaller than is claimed by government or by rightwing media commentaries which provoke occasional panics over immigration). ${ }^{6}$ Britain

\footnotetext{
${ }^{5}$ as of the 2001 census but the figure is probably now nearer $10 \%$

${ }^{6}$ for example, recent press coverage in the UK claimed that between 600,000 and 1 million migrant workers per annum from East and Central Europe had arrived in the UK since the accession of former
} 
now has a very diverse population - it is not unusual, for example, for cities with relatively small minority populations to accommodate more than fifty different languages and there are settled minorities in every local authority area in the UK.

Individual and institutional racism - that is abuse and assault by individuals or the maintenance of structures, mechanisms and processes which disadvantage people because of their ethnic origins - however, are continuing and, according to official statistics ${ }^{7}$, growing problems. In the last five years, the UK has seen a number of high level enquiries into aspects of the welfare state which have pointed to systematic racism; for example, the enquiry into the death of Steven Lawrence, a black teenager, and the failings of the police to respond effectively was just one of about thirty racially-motivated murders in the past ten years (McPherson, 1999); the enquiry into the death of Michael Bennett, a black man killed whilst being restrained in a psychiatric hospital (Blofeld, 2004); the enquiry into the racist murder of Zahid Mubarek, whilst in a prison cell, which is shortly to report but has attested to widespread racism in the prison service; the knifing and murder of Firsat Dag, a Turkish refugee, in a deprived housing estate in Glasgow; and a total of 69 racialized murders in the past ten years. Immigrants detained in government reception centres are now widely known to have been subject to systematic abuse and assault; police at a training centre have been recorded by an undercover TV reporter engaging in widespread racist abuse; and other enquiries into structural racism are ongoing.

Despite the fact that far-reaching legislation was introduced in 2000 to confront racism in public institutions, progress has been very slow and the UK Home Secretary has now called (again) for all public bodies to address racial discrimination within their services, backed by firm action, ethnic monitoring, public service agreements and inspection. Meanwhile, the police service records tens of thousands of incidents of racist abuse and attacks each year (a number which is recognized to be an underestimate of the real extent of the problem, the British Crime Survey reporting three times as many such incidents annually); the number of anti-semitic attacks has reached a peak in recent years; and the fascist British National Political Party, whose political platform has been based in part on repatriating immigrants, fielded a record number of candidates in the 2005 General Election. A MORI poll for the British Council revealed in 2000 that young people in other countries perceived Britons to be "arrogant, xenophobic ... racially intolerant ... and frequently drunk” (cited in Craig, 2003). A second poll found that roughly one-third of the UK population admitted that they had racist attitudes and that figure has apparently grown substantially in the past few years, in part because of the hostile government and media treatment of asylum-seekers and refugees, in part because of the growing Islamophobia generated by the so-called global "war on terror'.

One consequence of the 9/11 attacks in New York has been the introduction of legislation which has allowed suspected terrorists to be imprisoned for years without trial, and stopping and searching of suspects which, the Home Office admits, will disproportionately disadvantage people "of Muslim appearance" (whatever that might be). More recently, in the wake of bombings and attempted bombings in London, people

Soviet bloc states to the European Union in 2004. The true figure, over two years, was 447,000, i.e. roughly 200,000 per year.

${ }^{7}$ See for example Home Office statistics www.homewoffice.gov.uk/rds/stats and the outcomes of the UK British Crime Survey. 
of "unusual" dress and appearance have been apprehended on buses, trains and airplanes leading one senior police officer of Asian origin to say that a new offence, of "travelling whilst Asian," had been introduced by the police. None of this can be regarded as an approach which privileges respect to those who happen to dress or look differently. At a more modest level, there are a number of struggles being carried forward by minorities over aspects of their culture which, they argue, should be recognized and accepted within a multicultural society in which they also are, in theory at least, full citizens. Examples of this are the right for young women and girls to wear particular forms of clothing - the hijab and the jilbab - at school and at work, for respect for traditional forms of food preparation (there is currently a discussion about humane ways to kill animals in keeping with the principles of halal food preparation), and the right to open faith schools (the UK has had Christian schools for hundreds of years but government has recently argued that single faith schools when maintained by Muslims undermine community cohesion). In this context, it would be difficult, therefore, to argue that social justice - in a relational sense - is available to members of minority ethnic groups in the UK.

Equality of status is clearly, beyond the rhetoric of citizenship, unequally offered within the UK. The struggles by minority groups to assert their cultural rights have occasionally taken a violent form. In 1989, Salman Rushdie's book The Satanic Verses led to a fatwah, or implied sentence of death, being placed on him by orthodox Islamic clerics and he had to go into hiding for many years. More recently, tensions between what is described as the British culture of free speech and respect for other religions and cultures has been tested when performances of a play, Behtzi, which portrayed murder and abuse within a Sikh Temple, were abandoned as a result of a vigorous street protest by members of the Sikh community, a community which is incidentally in many ways one of the highest achieving minority groups within the UK. To date, however, no acts of violence have led to the deaths of those testing the boundaries between different cultures - as happened in the Netherlands when the filmmaker Theo van Gogh was killed allegedly by a member of an Islamic radical group because he satirized the treatment of women by Muslims. The converse - racist deaths of black and minority people however, is, as noted, a frequent occurrence. This is not to argue that there are not tensions in determining the parameters of acceptable behaviour or speech within the UK - indeed the events since 9/11 have brought these tensions into sharper focus. The point here is that minorities feel that their ability to assert their cultural rights are not being formally recognized, particularly in the current climate and that resorting to more strident or even violent protest is the only way in which they can have their viewpoint acknowledged. ${ }^{8}$

In terms of equality of opportunity, for example in terms of opportunity of access to goods, services, and, in particular, welfare provision the situation is no better. It is this situation which, as noted earlier, provides the basis for the state to compensate for the failure of the market to deliver goods and services on an equitable and socially just basis. Reviews of the entire provision of welfare and specific aspects of it (Modood et al., 1997; Craig, 1999; Craig, 2001; Parekh, 2002: Craig, 2003; Platt, 2003) within the UK suggests that access to welfare provision is unequally available. Indeed, racism in state welfare has a long pedigree, going back to the sixteenth century when the first Queen Elizabeth, at a time of economic depression within the UK, ordered all "negroes and blackamoors" to

\footnotetext{
${ }^{8}$ Martin Luther King argued that "riots are the language of the unheard." 
leave the country rather than allow them to receive poor law welfare support. These reviews show that opportunity to access the various aspects of welfare - housing, education, the labour market, social services, the health service - is shaped strongly by the dimension of ethnicity. Although this is not an iron law in the sense that some minority groups are now beginning to achieve well despite the obstacles placed in their way, certain minority groups - particularly those of African Caribbean, Bangladeshi and Pakistani origin and those from the more recently arriving groups - continue to be concentrated in the most deprived housing neighbourhoods and thus have access only to the schools with the worst conditions, poorest staffing provision and least good records of attainment (Gillborn and Mirza, 2000). They have greatest difficulty in accessing appropriate health provision (often because of the failure of health services to respond to specific cultural needs such as for interpretation, by ethnically-matched provision, or by providing female doctors for women patients), they are obstructed in terms of advancement in the labour market and their careers and often end up in the workplaces with the poorest working conditions, poorest pay and least security (Craig, 2003; Cabinet Office, 2003) and they are concentrated amongst those with the lowest incomes (Craig, 1999; Platt, 2003) .

The failure of the state welfare system to respond to the needs of minority groups is, in part, also a reflection of their failure to offer them the opportunity to participate adequately in important decision-making mechanisms - another aspect of the definition of social justice given above. Black and minority ethnic people have rarely had a formal voice in a wide range of policy initiatives such as neighbourhood renewal or voluntary sector development and funding streams to autonomous black and minority ethnic organizations remain marginal to most large-scale mainstream policy initiatives. Where government does consult minorities, there is an increasing sense that it tends to deal with what younger minorities now regard as the generation of older "community leaders" who are no longer regarded by many minorities as representing them (Jan-Khan, 2003). For example, at a recent Muslim summit called by Prime Minister Blair, no one under the age of 40 was present.

The definition of social justice drawn together earlier in this paper is also concerned, most crucially, with equality of outcomes. If one looks again across the whole range of welfare provision, outcomes for black and minority people - with a very few notable exceptions - are disproportionately poor compared with the population at large. For example, if we look at the pinnacle of political decision-making, the House of Commons, there are currently only 19 black and Asian MPs out of a chamber of 630 MPs--that is barely 3\% compared with a black and minority ethnic population of 8\%--and there has never been an Asian female MP although Asian women have been settled in the UK for more than two hundred years. Educational attainment--in terms of school qualifications, entry to higher education, achievement at the highest level of higher education--is, with some exceptions, far lower than the national average for most minority groups (for example there are very few black or Asian professors in UK universities - about $2 \%$ in all - and there are no black or Asian Vice-Chancellors or Principals in the 110 UK Universities). Even in those areas where some minorities do well - such as medicine - there is a glass ceiling which stops them achieving the highest honours. Thus, as noted earlier, black and Asian hospital consultants often find themselves working in the poorest or most isolated hospitals because they are unable to 
secure posts in the more prestigious teaching hospitals. In the police force, barely $2 \%$ of the UK force nationally is from black and ethnic minorities and there is only one black Chief Constable. There are no black Directors of Social Services in the more than 150 local authority social services departments. Whilst about $5 \%$ of social services staff are from minorities, that figure drops to less than $2 \%$ in social services management posts.

In education, the area where advantage and attainment might best be promoted, disadvantage and discrimination are built into the education system from a very early age. Despite the fact that each of the main ethnic groups has achieved higher standards than ever before, a report commissioned by OFSTED, the government's inspection body, found a few years ago that black and ethnic minority pupils are disadvantaged systematically by the education system (Gillborn and Mirza, 2000). Most strikingly, the researchers concluded that one ethnic group (black young people) actually entered school 20 percentage points in advance of the average but left it 21 points behind the average, a deeply disturbing reflection on racism within the formal educational system. Ironically, for one outcome, young black people scored highly - but this was for the number of permanent exclusions from school. These were the result, it appears, of a complex range of factors but included racist responses from schools which disproportionately label and exclude black school pupils (Cooper, 2004). In the field of health, a recent survey of pay awards in the NHS found them riddled with racism. In terms of mental health, black service users are more likely to be (mis)-diagnosed as schizophrenic, contained in psychiatric institutions and treated with electroconvulsive therapy (Rai-Atkins, 2002). This--and a much wider range of evidence--demonstrates that in terms of equality of outcomes, black and minority groups do not achieve anything like social justice. This is not an argument that every person, every structure, or every policy in the UK concerned with the provision of welfare is racist, far from it, but institutional and individual racism remain prevalent to a large degree and, for most minorities, have a determining effect on their life chances.

Faced with this lack of equality of status, of opportunity, of outcome, and of respect and recognition, what should be the political strategy pursued by the UK's minorities - and those in other countries for that matter, to achieve social justice? The gradualist strategy of parliamentary and political representation--at every level, from central government to local government, the voluntary sector and so on--has clearly not succeeded in helping minorities get more effective control of the conditions under which they live. Some minority groups have pursued a separatist strategy through the creation of autonomous organizations, faith schools and separate welfare agencies such as black housing associations. These might have given a degree of control to such groups but are often situated in a broader context of a lack of resources and a struggle to survive. Ironically, in some areas, minorities have been accused of pursuing a policy of segregation in relation to housing; a classic example of blaming the victim since for many minorities, there is no question of choice. Because of limited access to social housing, to mortgage finance and so on, it is only in the poorest quality housing areas that they have been able to access accommodation at all. As Susan Smith (1989), puts it, this concentration in certain areas does not explain why minorities "should pursue this [choice] in the more run-down segments of the housing stock [with poor quality housing, dangerous neighbourhoods and inadequate health and education provision], rather than in 
areas where they could secure the symbolic and economic benefits associated with suburban life” (p. 130).

Over the past forty years, there have been increasing outbreaks of interracial violence in some cities, most recently in northern cities three years ago. Whilst some of these disturbances - or riots, as the media like to call them - have been prompted by single events, such as the arrest or death of a black individual, increasingly some minority commentators are viewing them as a political response to the cumulative disadvantage faced by Britain's minorities over the past sixty years or more (Jan-Khan, 2003). In many parts of Britain, particularly rural areas and areas where there is only a relatively small population of black and ethnic minorities, there is still a significant level of denial that racism is a problem (Darr et al., 2005). This suggests that these disturbances will continue to erupt until the UK government, and the population as a whole, recognize the claims of social justice for its entire people. It also suggests that the process of negotiation over the way in which social justice can be achieved for Britain's minorities has hardly started. At present, the language of the government - of integration and assimilation - often tends towards the language of the 1950s, where minorities were expected to surrender most aspects of their culture (perhaps being left with "just drumming and dancing" to assert their heritage) as a condition of achieving the status of full citizens. As we have seen, becoming legal citizens does not guarantee equality of status, opportunity or outcomes because of the impact of racism and this is a wider struggle which needs to be engaged with in order to promote social justice for all.

Social justice, as defined in the first part of this article, then is not a reality for Britain's minorities. In the current political climate, the tendency is increasingly to deny minorities effective expression of their cultural and religious rights. The wider agenda of ensuring equality as citizens - in terms of status, opportunity and access - has, despite legislation and political rhetoric - hardly begun to be addressed. New Labour's political project has barely scratched the surface of social justice for Britain's minorities and indeed, for that matter, despite gains in a few areas, the poorest and most marginalized in the UK as a whole. 


\section{References}

Blofeld, Sir J. (2004). Report into Inquiry into the Death of Michael Bennett. London: Department of Health.

Butt, J. and O’Neil, A. (2004). Let's Move on: Black and Minority Ethnic Older People's Views on Research Findings. York: Joseph Rowntree Foundation.

Cabinet Office (2003). Ethnic Minorities in the Labour Market. London: Cabinet Office.

Castles, S. (2000). Ethnicity and Globalisation. London: Sage.

Cooper, C. (2004). Understanding School Exclusion. Nottingham: Education Now.

Craig, G. (1999). 'Race’, Poverty and Social Security in J. Ditch (Ed.). An introduction to social security. London: Routledge.

Craig, G. (2001). 'Race' and Welfare. Inaugural lecture as Professor of Social Justice, Hull: University of Hull.

Craig, G. (2003). 'Ethnicity, Racism and the Labour Market: a European Perspective' in J-G. Andersen and P. Jensen, (Eds.). Citizenship, welfare and the labour market, Bristol: Policy Press.

Craig, G. (2006). Black and Minority Ethnic Children. In G. Preston (Ed.), At Greatest Risk. London: Child Poverty Action Group.

CSJ (Commission for Social Justice) (1994). Social Justice: Strategies for National Renewal. London: Verso.

Darr, A., Atkin, K. and Craig, G. (2005). Ethnic Minorities in a Rural labour market, York: North Yorkshire Learning and Skills Council.

Dean, H. and Melrose, M. (1999). Poverty, Riches and Social Citizenship. London: Routledge.

Donnison, D. (1998). Policies for a Just Society. Basingstoke: Macmillan.

Doyal, L. and Gough, I. (1991). A Theory of Human Need. Basingstoke: Macmillan.

Fraser, N. (2001). Recognition without Ethics? Theory, Culture and Society, 18(2-3), 21-42.

DWP (2005). Opportunity for All: Sixth Annual Report, London: The Stationery Office/Department of Work and Pensions.

Galabuzi, G-E. (2006). Canada's Economic Apartheid: the Social Exclusion of Racialized Groups in the New Century. Toronto: Canadian Scholars Press.

Gillborn, D. and Mirza, H. (2000). Educational Inequality: Mapping Race, Class and Gender, London: Institute of Education and Middlesex University.

Goodlad, R. (2005). Scottish Homelessness Policy: advancing Social Justice? Scottish Affairs, No 50, Winter, 68-105.

Gordon, D., Adelman, L., Ashworth, K., Bradshaw, J., Levitas, R., Middleton, S., Pantazis, C., Patsios, D., Payne, S., Townsend, P. and Williams, J. (2000). Poverty and Social Exclusion in Britain. York: Joseph Rowntree Foundation. 
Henderson, P. and Kaur, R. (Eds.) (1999). Combating Rural Racism in the UK. London: Community Development Foundation.

Hirst, P. and Thompson, G. (1999). Globalisation in Question. Cambridge: Polity Press.

Jan-Khan, Manawar (2003). The Right to Riot. Community Development Journal, Vol. 38 No 1: 32-42.

JRF (2004). Overcoming Disadvantage: an Agenda for the Next 20 Years. York: Joseph Rowntree Foundation.

Lister, R. (2003). Citizenship: Feminist Perspectives ( $2^{\text {nd }}$ edition). Basingstoke: Palgrave.

Lister, R. (2004). Poverty, Cambridge: Polity Press.

Marshall, T.H. (1950). Citizenship and Social Class, in T.H. Marshall and T. Bottomore, (1992) Citizenship and Social Class, London: Pluto Press.

McPherson, Sir W. (1999). Inquiry into the death of Steven Lawrence. London: HMSO.

Miller, D. (2001). Principles of Social Justice. Cambridge, Mass and London: Harvard University Press.

Modood, T., Berthoud, R. et al. (1997). Ethnic Minorities in Britain. London: Policy Studies Institute.

NICF (2001). Annual Report. Belfast: Community Foundation for Northern Ireland.

Parekh, B. (2002). Commission of Enquiry into the Future of a Multi-ethnic Britain. London: Runnymede Trust.

Paxton, W. and Dixon, M. (2004). The State of the Nation: an Audit of Injustice in the UK. London: Institute of Public Policy Research.

Plant, R. (2000). Social Justice in R. Walker (Ed.) Ending Child Poverty. Bristol: Policy Press.

Platt, L. (2003). Parallel Lives? London: Child Poverty Action Group.

Rai-Atkins, A. (2002). Best Practice in Mental Health Advocacy for Black, Caribbean and South Asian Users. York: Joseph Rowntree Foundation.

Rawls, J. (1971). A Theory of Justice. Oxford University Press, Oxford.

Scottish Executive (2003). Social Justice: a Scotland where Everyone Matters. Edinburgh: Scottish Executive.

Smith, Susan J. (1989) The Politics of Race and Residence. Cambridge: Polity Press.

UNDP (1997). Human Development Report: 1993. Oxford: Oxford University Press.

Venters, G. (2002). Globalisation: Contested Meanings and Alternative Futures. Concept, 12(1): 5-10.

Young, I.M. (1990). Justice and the Politics of Difference. Princeton: Princeton University Press. 